\title{
Proceedings
}

\section{Walkability, digital technologies and internal area tourism}

\author{
Ginevra Balletto ${ }^{1}$, Ladu Mara ${ }^{1,}$, Milesi Alessandra ${ }^{1}$, Battino Silvia ${ }^{2 *}$, Giuseppe Borruso ${ }^{3}$ \\ 1 Department of Civil and Environmental Engineering and Architecture. University of Cagliari, Italy, \\ balletto@unica.it; maraladu@hotmail.it; alessandra.milesi@gmail.com \\ 2 University of Sassari - Department of Economics and Business; sbattino@uniss.it \\ 3 Department of Economics, Business, Mathematics and Statistics "Bruno de Finetti", University of Trieste, \\ Via Tigor 22, 34127 Trieste, Italy, GIUSEPPE.BORRUSO@deams.units.it \\ * Correspondence: Silvia Battino, sbattino@uniss.it
}

\begin{abstract}
European strategies for rethinking rural interior spaces, albeit rich in potential productive resources, are constantly plagued by significant depopulation rates and difficult access to primary services. The reactivation of spaces is the subject of national and international scientific dialogue through multiple approaches including slow tourism. The construction of a multifunctional network of space also connected to the most recent technological innovations motivates various projects capable of regenerating local economies. This work aims to highlight, in the case study of Sardinia, the role of sustainable "rural walks" (walkability) as promoters of a new accessibility to internal areas and a different and more structured organization of the tourist offer based on a slow use of the territory.
\end{abstract}

Keywords: slow tourism; sustainable tourism; internal areas.

Citation: Balletto, G.; Ladu M.; Milesi A.; Battino, S., 2022, Borruso, G. Walkability, digital technologies and internal area tourism. SUPTM 2022 conference proceedings sciforum-054505 https://doi.org/10.31428/10317/10583

Publisher's Note: UPCT and Sciforum stays neutral with regard to jurisdictional claims in published maps and institutional affiliations.

Copyright: (c) 2022 by the authors. Submitted for possible open access publication under the terms and conditions of the Creative Commons Attribution (CC BY) license (https://creativecommons.org/license s/by/4.0/).

\section{Introduction}

The European strategy for the revitalization of inland areas firmly supports local development policies that leverage technology, the sustainability of transport and tourism to improve accessibility and the criticalities of rural areas [1]. Walkability is part of the numerous regeneration projects of local development, also and above all for the post COVID-19 [2]. In fact, the planning of pedestrian areas, while being the prerogative of urbanized areas, is increasingly explored also in rural areas as an interesting element to take advantage of small rural realities $[3,4]$. We therefore want to evaluate rural routes designed in other parts of Sardinia according to the model of the "Santa Barbara Mining Path", Sulcis-Iglesiente in Sardinia (Italy), to evaluate the degree of predisposition to pedestrian use of natural and rural contexts of great importance of the landscape deriving from the accessibility and intermodality. In this sense, we want to evaluate, through a conceptual approach, how the gap between the reference model and the proposals derived from it can be overcome. The paper is developed in the following paragraphs: area of study, conceptual approach, results and conclusions.

\section{Area of study}

The Sulcis-Iglesiente region is located in the south-western part of the island of Sardinia which has seen its environmental and socio-economic evolution linked to the world of 
mining. The mines abandoned over time have been converted into sites of cultural interest whose enhancement, from a sustainable perspective and under the guidance of slow tourism, aims to improve local development [5]. The mapping from a tourist point of view of the ancient miners' paths highlights a set of itineraries that are part of the Geo-Mining Historical-Environmental Park of Sardinia. The system of paths of the "Santa Barbara Mining Path", and its intrinsic and extrinsic characteristics constitutes a best practice, so much so that it has been proposed for replication in other similar contexts in Sardinia (Fig. $1)$.

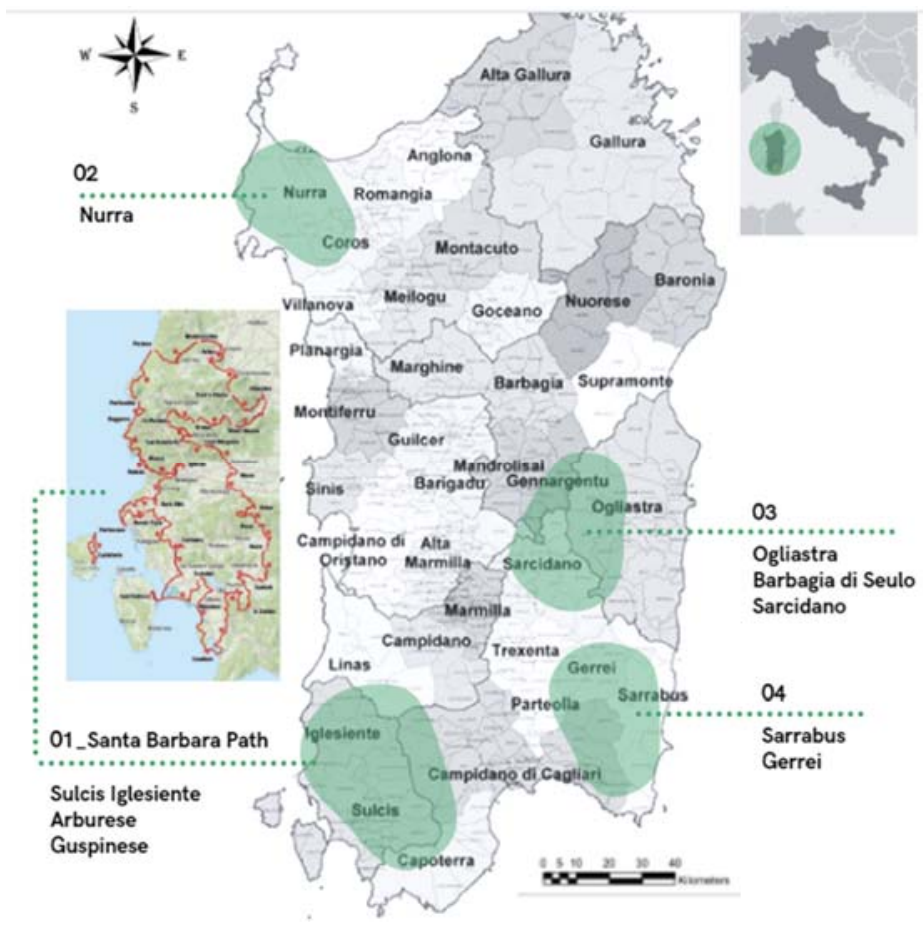

Figure 1. Location of mining path of Santa Barbara and new proposal (02-04), Sardinia, Italy (Author: Balletto G., 2021)

\section{Conceptual approach}

From the elaboration of the ICE index (Inclusion of Community and Environment) in a previous research [6] with the aim of supporting the design decision-making processes for all in the paths in internal and rural areas, it was possible to highlight the gap with the reference (01 part). In particular, with this research it intends to highlight the main critical elements that arise from the ICE index assessment to identify improvement strategies.

In particular, the Santa Barbara Mining Path (good practice) and the replication proposals (02-04), allow us to highlight how although the 01 path is good practice, it was not designed according to the universal design (Fig. 2). 


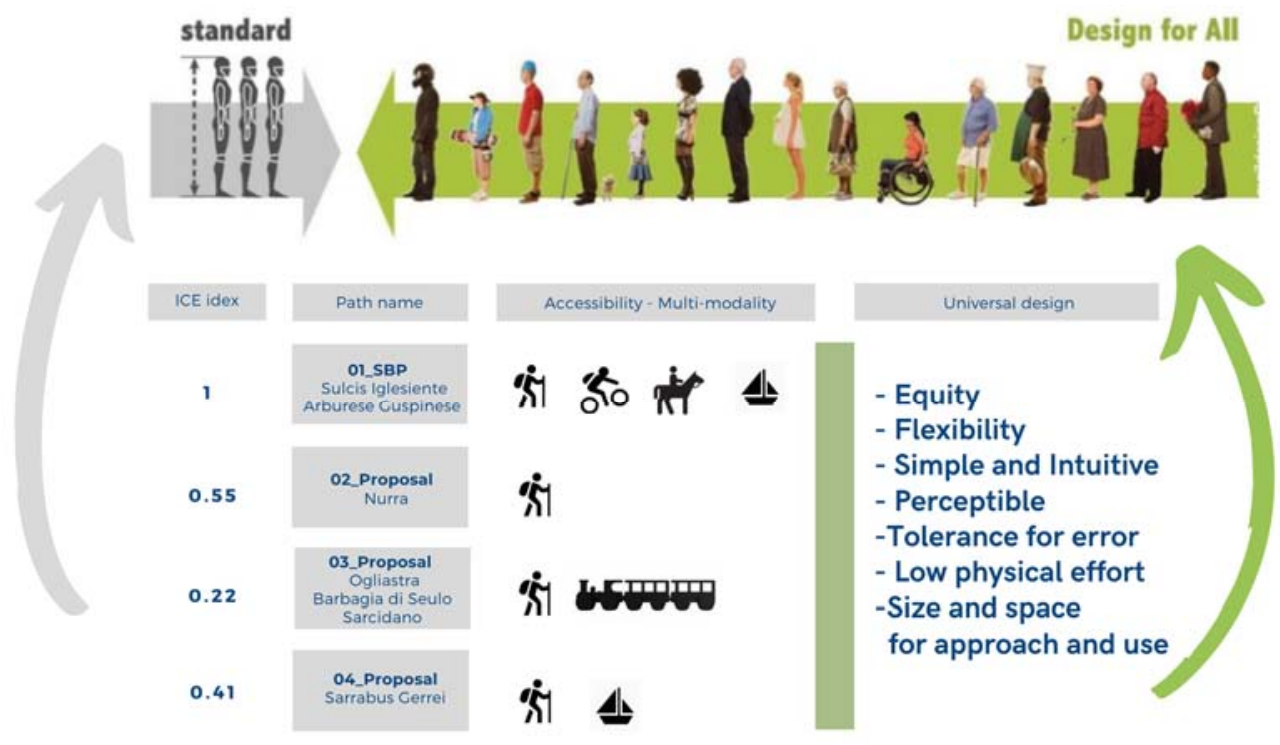

Figure 2. Comparative analysis 01-04 Mining Paths (Author: Balletto G., 2021)

Similarly also the 02-04 paths, although they involve 472 cultural and landscape assets and with 20 municipalities involved, the related draft is not based on the universal design. In this sense, it is believed that this articulated patrimonial wealth must be exploited in order to transform the peripheral condition of these rural areas to converge towards a diversified, sustainable and inclusive tourist offer [7]. The other weaknesses observed along the itineraries (02-04 paths) can be seen in the limited participation by different stakeholders to activate development projects. There are also important gaps in the digitalization of natural and historical-cultural information, and these are compounded by limited forms of mobility and the absence of a rural hospitality network. In this case, the hospitality is expressed through 90 agritourisme that have difficulty in creating multifunctional activities able to revitalize the territory outside of the summer [8].

\section{Results}

The proposals of the new paths, while constituting an important initiative, nevertheless present a not negligible deficit that derives from the reference model (path 01) designed according to the traditional approach of standard users. For this reason, if you want paths 02-04 to constitute an inclusive and sustainable offer, their relative design must be based on the universal design paradigm, that is, to facilitate a continuous process of space usability which combines the three dimensions of accessibility (structural, experiential and informative). This would allow for even higher performance than the reference model to be achieved. Furthermore, universal design offers at the same time important elements to adapt what until now has been considered a best practice (path $01)$.

\section{Conclusions}

The slow tourism philosophy, intrinsic to the definition of rural tourism, combined with sustainable mobility and greater walkability of the sites, brings benefits both in environmental terms (conservation of natural resources, no emission of pollutants) 
and in social and economic terms (higher quality travel and life for residents, increased security and social interaction) [9]. The 02-04 proposals for paths in Sardinia (Italy), although rich in a vast cultural heritage, require a more careful and structured organization of the accessibility of the territory. The approach that is outlined is multiscalar; from the objectives of the 2030 Agenda, to universal design with the support of thimbles technologies (from concept to use). Finally, particular attention should be paid to the intermodal nodes and in particular to those of the marinas, the real gates for the inland areas. The current transitions underway (ecological, digital and energetic) require a rethinking of the project paradigms especially for those of the network such as paths, which constitute tangible and intangible elements of the past, present and future, possibly prosperous. The research will continue with the development of design guidelines for universal design in combination with the ICE index.

\section{References}

1. Battino, S.; Lampreu, S. The Role of the Sharing Economy for a Sustainable and Innovative Development of Rural Areas: A Case Study in Sardinia (Italy). Sustainability 2019, 11 (3004), 1-20 (https://doi:10.3390/su11113004).

2. Balletto, G.; Milesi, A.; Ladu, M.; Borruso, G. A Dashboard for Supporting Slow Tourism in Green Infrastructures. A Methodological Proposal in Sardinia (Italy). Sustainability 2020, 12, 3579 (https://doi.org/10.3390/su12093579).Frost, S. S.; Goins, RT.; Hunter, R. H.; Hooker, S. P.; Bryant, L. L.; Kruger, J.; Pluto, D. Effects of the built environment on physical activity of adults living in rural settings. Am J Health Promot. 2010, 24(4), 267-283 (https://doi.org/10.4278/ajhp.08040532).

3. Kegler, M. C.; Alcantara, I.; Haardörfer, R.; Gemma, A.; Ballard, D.; Gazmararian, J. Rural neighborhood Walkability: implications for assessment. Journal of Physical Activity and Health 2015, 12 ( Suppl. 1), 40-45 (https://doi.org/10.1123/jpah.2013-0431).

4. Balletto, G., Milesi, A., Battino, S., Borruso, G., \& Mundula, L. Slow tourism and smart community. The case of Sulcis-Iglesiente (Sardinia-Italy). In International Conference on Computational Science and Its Applications. Springer, Cham, 2019, 184-199 (https://doi.org/10.1007/978-3-030-24311-1_13).

5. Balletto, G., Borruso, G., Milesi, A., Ladu, M., \& Mundula, L. Ancient Mining Paths and Slow Tourism. Assessments and Challenges in Sardinia (Italy). In International Conference on Computational Science and Its Applications (Eds.); Springer, Cham, 2021, pp. 275-287 (http://dx.doi.org/10.1007/978-3-030-87016-4 21).

6. Battino, S.; Balletto, G.; Borruso, G.; Donato, C. Internal Areas and Smart Tourism. Promoting Territories in Sardinia Island. In Computational Science and Its Applications - ICCSA 2018. ICCSA 2018. Lecture Notes in Computer Science; Gervasi O. et al. (Eds.); Springer: Cham, 2018; 10964, pp. $44-57$ (https://doi.org/10.1007/978-3-319-95174$\underline{44})$.

7. Brundu, B.; Battino, S.; Manca, I. The sustainable tourism organization of rural spaces. The island of Sardinia in the era of "staycation". Proceedings of ICC2021 - 30th International Cartographic Conference, Florence (Italy) 14-18 december 2021, 4, 15, 2021 (https://doi.org/10.5194/ica-proc-4-15-2021).

8. Wieckowski, M. Will the Consequences of Covid-19 Trigger a Redefining of the Role of Transport in the Development of Sustainable Tourism? Sustainability 2021, 13, 1887, 1-15 (https://doi.org/10.3390/su13041887). 